\title{
Simplified Scale Modeling of Turbulent Flame Spread with Implication to Wildland Fires
}

\author{
I. EMORI and Y. IGUCHI \\ Department of Mechanical Engineering \\ Seikei University, Musashino \\ Tokyo 180, Japan
}

\author{
K. SAITO \\ Department of Mechanical Engineering \\ University of Kentucky \\ Lexington, Kentucky 40506, USA
}

\author{
I. S. WICHMAN \\ Department of Mechanical Engineering \\ Michigan State University \\ East Lansing, Michigan 48824, USA
}

\section{ABSTRACT}

Scale-model experiments were performed to measure rates of horizontal and up-slope flame spread for models of stem fires (fires of the tree crowns and the fibrous bark on the tree boles) and grass fires and radiant heat flux to the environments. This work was motivated by previous studies of stationary fires in which two different types of scaling laws were proposed, both of which were applicable for turbulent flame spread. Data obtained include radiant heat fluxes, flame heights and depths, and pyrolysis front locations. Comparisons of the measurements with the scaling laws aid understanding of scaling effects on turbulent flame spread; scaling laws for the flame spread in the wildiand are suggested.

\section{INTRODUCTION}

Turbulent flame spread over horizontal and up-slope surfaces is an important problem arising in both urban and wildland fires

However, our current knowledge is insufficient to allow even approximate prediction of horizontal and up-slope turbulent flame spread rates in wildland environments . This work attempts to develop an understanding of the scaling laws for horizontal and up-slope flame spread for use in developing better prediction methods and fire codes.

In our previous study scaling laws for stationary fires were investigated for large-scale liquid fuel pools and wood cribs of various sizes. The study did not involve flame spread. It was found that two length scaling was applicable for 1iqyid fuel pool fires and that single length scaling for wood-crib fires 8 . Experiments were performed with/without wind blowing conditions for tank diameters up to $10 \mathrm{~m}$ and crib lengths up to $1 \mathrm{~m}$. We now extend this study to the case of spreading flames in order to determine whether or not the two different scaling concepts found for stationary fires are still applicable.

To this end, we designed basic and practical scale models for spread tests, and found that two different scaling concepts were indeed applicable for flame spread. The stem fire models were made with paper strips coated with commercially available candle wax which were vertically imbedded in a Marinate board. Such a model burns at moderate speed and releases enough heat to create turbulent flames; the observed spread behavior therefore resembles the basic characteristics of wildland stem fires. Three different sizes of the paper-strip model were designed for laboratory tegts. The different types of models are discussed in the earlier works ${ }^{10-12}$; all of those models are in the laminar flow regime, 
while present models are turbulent. Since the characteristics of grassland fires are different from those of stem fires; excelsior of six different sizes was employed as another fuel to understand fundamental spread behavior over grassland. Experiments were performed for models of different sizes, and scaling laws on spread behavior were evaluated. In addition to these (basic) model tests, grassland with a surface area of $17.5 \mathrm{~m} \times 20 \mathrm{~m}$ was used for a large-scale fire test ${ }^{13}$. The corresponding geometrically similar grassland models of one-tenth and one-twenty fifth scale were then designed in our laboratory to further confirm the scaling laws for large fires.

To develop the scaling laws, a fundamental physical interpretation of the general aspects of wildland fires is necessary. Such fires generally involve well developed turbulent flames. The virgin fuel is heated primarily by flame radiation and convection of the hot gases. Fire brands 14,15 are one of the important transfer modes associated with spot fire; there is some understanding of the mechanism , which is not included in our model. The gasification rate of the fuel is mainly controlled by the balance of radiative and convective energy input to the virgin fuel, the latent heat of the fuel and heat stored in the virgin fuel associated with temperature rise. $16^{\text {Heat }}$ conducted from the burned fuel to the virgin fuel is negligible ${ }^{16}$. Since there is a major difference between fires of the paper strips and excelsior (as a porous fuel), separate and distinct scaling laws are developed for flame spread over these two types of fuel. General goyerning equations and scaling concepts axe fully described by Williams and Spalding 18 respectively for a wide range of fire phenomena. The scaling laws are derived in Section 2 by selecting out the governing physical quantities ${ }^{\text {. }}$

\section{SCALING LAWS}

The interpretation of fire spread explained above addresses the following major forces and heats. Figure 1 shows schematics of our mode1; the variables used there are defined in the nomenclature section.

$$
\begin{aligned}
& F_{i}=\rho_{1} \ell_{2} L_{a} u^{2}, F_{b}=\Delta \rho_{1} \ell_{2} L_{w} L_{a} g, Q-\phi q_{f} \rho_{f} \ell_{2} L_{w}-I_{w} t, \\
& Q_{r}=E \ell_{2} L_{e} t, Q_{c 1}=c_{p} \rho_{1} L_{a} \ell_{2} L_{e} \Delta \theta_{1}, Q_{c 2}=c_{2} \rho_{f} \ell_{2} H L L_{e} \Delta \theta_{2}, \\
& Q_{\lambda}=\lambda \rho_{f} \ell_{2}{ }^{H L} e_{e} .
\end{aligned}
$$
numbers.

Seven physical quantities yield the following six independent pi-

$$
\begin{aligned}
& \pi_{1}=\frac{F_{i}}{F_{b}}=\frac{\rho_{1}{ }^{2}}{\Delta \rho_{1} L_{w} g} \quad, \quad \pi_{2}=\frac{Q_{r}}{Q}=\frac{E \ell_{2} L_{e}}{I L_{w}} \\
& n_{3}=\frac{Q_{c 1}}{Q}=\frac{c_{p} \rho_{1} L_{a} V \Delta \theta_{1} \ell_{2}}{I_{w}}, \pi_{4}=\frac{Q_{c 2}}{Q}=\frac{L_{e}}{L_{w}} \\
& \pi_{5}=\frac{Q_{\lambda}}{Q}-\frac{\lambda L_{e}}{\phi q_{f} L_{w}}, \pi_{6}=\frac{F_{i} u t}{Q}=\frac{\rho_{1} L_{a} u^{3} \ell_{2}}{I L_{w}}
\end{aligned}
$$

Here, $V=L_{e} / t$ and $I=\phi q_{f} \rho_{f} l_{2} H / t$. The requirement for similarity between model and full-scafe system is that all of the pi-numbers must be 


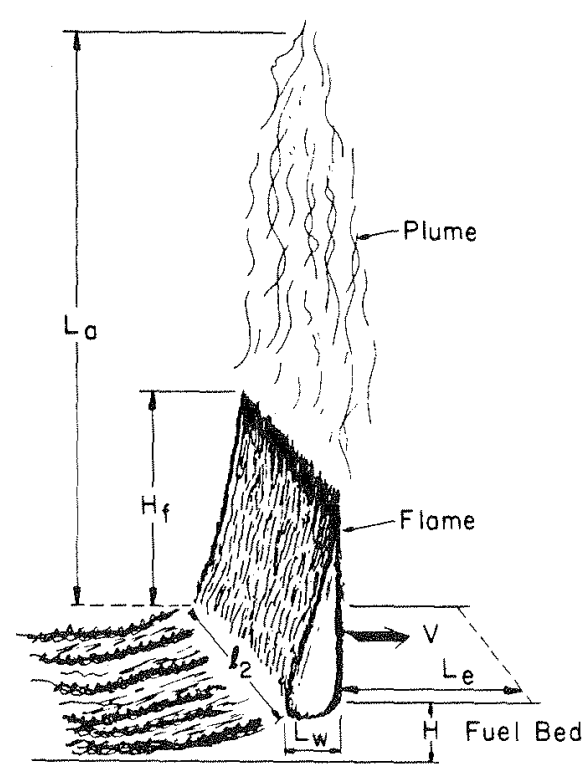

Fig. 1. Schematics of model.

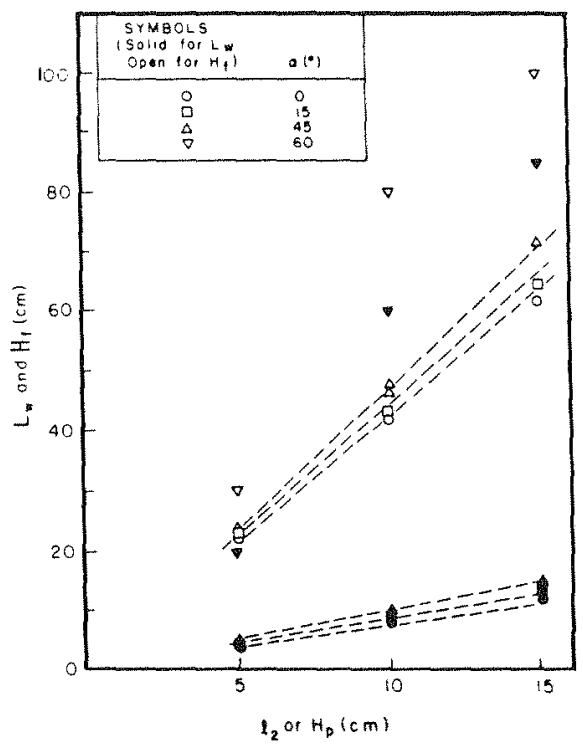

Fig. 2. Flame height and depth as a function of fuel bed width and height for paper strip model.

identical in both; $\pi_{i}=\pi_{i}^{\prime}, i=1$ to 6 , where' denotes the model. Some pi-numbers are famijiar, e.g., $\pi_{1}$ is Froude number and $\pi_{6}$ first

identified by Byram as the ratio of power of wind to the power of the fire has been used to explain fire plume behavior.

\subsection{Horizontal Fires of Paper Strips in the Absence of Wind}

In this case the spread rate is controlled by natural convection around each strip and by radiation from the flame. The effects of natural convection may remain nearly the same regardless of bed size if the beds were made of strips with the same width and the same height, imbedded in the same pitch. If the experiments are performed using the same fuel and under the same ambient conditions with retaining geometrical similarity of the bed, the following parameters are identical for prototype and models; i.e.,

$\rho_{1}=\rho_{1}^{\prime}, \rho_{f}=\rho_{f}^{\prime}, q_{f}=q_{f}^{\prime}, c_{p}=c_{p}^{\prime}, c_{2}=c_{2}^{\prime}, \Delta \theta_{1}=\Delta \theta \dot{1}$,

$\Delta \theta_{2}=\Delta \theta_{2}^{\prime}, \quad \lambda=\lambda^{\prime}, \Delta \rho_{1}=\Delta \rho_{1}^{\prime}$ and $g=$ const.

By assuming the following conditions,

$\phi=\phi^{\prime}, \ell_{2} / L_{w}=\ell_{2}^{\prime} / L_{w}^{*}, L_{e} / L_{w}=L_{e}^{\prime} / L_{w}^{\prime}, L_{a} / \ell_{2}=L_{a}^{\prime} / \ell_{2}^{\prime}$

The identities of $\pi_{4}$ and $\pi_{5}$ are satisfied. The rest of the pi-numbers must obey a functional relationship of the form.

$$
\Phi\left(u^{2} / L_{w}, E \ell_{2} / I, \quad L_{a} V / I, \quad L_{a} u^{3} / I\right)=0
$$


The identities of $\pi_{1}, \pi_{2}$ and $\pi_{3}$ yield,

$$
\mathrm{u} / \mathrm{u}^{\prime}=\sqrt{\mathrm{L}_{\mathrm{w}} / \mathrm{L}_{\mathrm{w}}^{\prime}}-\mathrm{C}^{\prime} \text { and } \mathrm{V} / \mathrm{V}^{\prime}=\mathrm{E} / \mathrm{E}^{\prime} \cdots-(5) \text {. }
$$

While $\pi_{6}$ can be released from the requirement of similarity for these type of fires. Note that the velocity $u$ as related to the motion of air and gas and the velocity $V$ as related to the spread rate do not necessarily have a common scaling in this model.

\subsection{Up-slope Fires of Paper Strips and Porous Fuel Fires}

In contrast to the horizontal fires of paper strips, buoyancy and inertia forces begin to affect the spread rate. When the fuel bed tilt angle is small, these effects are also small; as it increases, these effects begin to play a dominant role in the spread rate. Experiments showed that an abrupt change of flame shape and rapid spread occured at a tilt angle of $60^{\circ}$, so that the geometrical similarity of the flame was no longer obtained. With further increase of the bed tilt angle, the spread rate increased further. At $90^{\circ}$, upward spread occurs with an abruptly fasf 5 read rate whose characteristics are fully described elsewhere $5,21,22$. Therefore, there is a definite limit of the scaling laws discussed here; our model does not include spread phenomena whose bed tilt angle is greater than approximately $60^{\circ}$. Flame spread mechanism on the excelsior is different from that for paper strips, as will be discussed in section 3; that is, air flow entrained in the fuel interior through the excelsior surface may augment combustion even when the fue 1 bed is horizontal. Geometrical similarity, given by the ratio of flame height and flame depth to the fuel bed height or the fuel bed width, is retained as seen in Fig. 2 for $\alpha=0^{\circ}$ through $\alpha=45^{\circ}$. Therefore, for this type of fire, the characteristic length related to the motion of air and gas, must be represented by the characteristic length of the fuel bed. Thus, the simple relationship $u / u^{\prime}=V / V^{\prime}$ will be deduced. If we apply this relationship to the relationships (4) and (5), we obtain

$$
\mathrm{u} / \mathrm{u}^{\prime}=\mathrm{V} / \mathrm{V}^{\prime}=\mathrm{E} / \mathrm{E}^{\prime}=\sqrt{\mathrm{L}_{\mathrm{w}} / \mathrm{L}_{\mathrm{w}}^{\prime}} \cdots . . .(6) .
$$

Since the characteristic time related to fuel pyrolysis can be expressed as $t=\mathrm{L} / \mathrm{N}$, by applying the assumption (3) the scaling relationship for $t$ becomes, $t / t^{\prime}=\sqrt{L_{W} / L_{w}^{\prime}} \ldots . . .(7)$.

The scaling laws derived here are compared with the experimental results in section 3 . Since $\pi_{6}$ was not included in the above scaling, the role of $\pi_{6}$ should be explained here. Albini. 23 investigated its role in wind blown flames from line fires and found it a powerful predictor. In line fires $L_{w}$ is small compared with $\ell_{2}$ and $H_{f}$, so that $L_{w}$ may stay constant regardless of $\ell_{2}$ and $\mathrm{H}_{\mathrm{f}}$ change. If this ${ }^{\mathrm{W}}$ is the case, by applying (2), (3), (6) and (7) to $\pi_{6}, \pi_{6}=\rho_{1} \mathrm{~L}_{\mathrm{a}} \mathrm{L}_{\mathrm{w}} / \phi \mathrm{q}_{\mathrm{f}} \rho_{\mathrm{f}}^{\mathrm{H}}-\mathrm{L}_{\mathrm{a}} / \mathrm{H}$. Therefore $\pi_{6}$ becomes constant under the retained constant ratio of are plume height to fuel height.

\section{MODEL EXPERTMENTS}

\subsection{Two Basic Scale Models}

Paper stxips coated with candle wax and excelsior of several different sizes, as listed in Tables 1 and 2 , were used for horizontal and up-slope spread tests. The paper strips were vertically imbedded in a $1 \mathrm{~cm}$ thick Marinite board at a $0.5 \mathrm{~cm}$ square pitch. Three different sizes of the paper strip model were used. Commercially available candle 
Table 1. Configurations of paper strip model.

\begin{tabular}{|lcccc|}
\hline Model & $\mathrm{H}_{\mathrm{n}}(\mathrm{cm})$ & $\mathrm{w}(\mathrm{cm})$ & $\mathrm{L}(\mathrm{cm})$ & $l_{2}(\mathrm{~cm})$ \\
\hline $\mathrm{M}_{\mathrm{p} 1}$ & 5 & .5 & .5 & \\
$\mathrm{M}_{\mathrm{p} 2}$ & 10 & .5 & .5 & 150 \\
$\mathrm{M}_{\mathrm{p} 3}$ & 15 & .5 & .5 & \\
\hline
\end{tabular}

Table 2. Configurations of excelsior model.

\begin{tabular}{|cccc|}
\hline Model & $\mathrm{H}_{\mathrm{e}}(\mathrm{cm})$ & $\mathrm{L}(\mathrm{cm})$ & $l_{2}(\mathrm{~cm})$ \\
\hline $\mathrm{Me}_{1}$ & 5 & & 5 \\
$\mathrm{Me}_{2}$ & 8 & 100 & 8 \\
$\mathrm{Me}_{3}$ & 10 & & 10 \\
$\mathrm{Me}_{4}$ & 15 & & 15 \\
$\mathrm{Me}_{5}$ & 20 & 150 & 20 \\
$\mathrm{Me}_{6}$ & 30 & & 30 \\
\hline
\end{tabular}

wax was used for coating the paper strips. First the paper strips were dried, then soaked in the liquid wax. Shortly after the strip-surface was saturated with the wax, it was removed from the container and was exposed to the air at room temperature for cooling. The thin layer of solid wax formed on the surface was smoothed with a knife in order to make a uniform coating thickness of $0.5 \mathrm{~mm}$. Exploratory tests indicated that the $0.5 \mathrm{~mm}$-thickness coating gave a reasonably moderate spread rate, so that we used this thickness for all the three paper strip models. The geometrical configuration of the model is shown in Table 1 .

Excelsiors used were made from Japanese pine, whose average element cross section was $0.5 \mathrm{~mm} \times 1.5 \mathrm{~mm}$ and average element length $10 \mathrm{~cm}$. Six different sizes of the excelsior with the same packing density $(0.012$ $\mathrm{g} / \mathrm{cm}^{3}$ ) were used (see Table 2). Prior to the experiment, all samples were stored in a conditioning room, at $23 \pm 3^{\circ} \mathrm{C}$ with a relative humidity of $508 \pm 58$ for a week, a long enough period to equilibriate moisture. To decide a minimum model dimension that retains turbulent flame characteristics, exploratory tests were undertaken and $M$ for the paper strip model and $M_{e l}$ for the excelsior model were determined as shown in Tables 1 and 2 .

Ignition was made for both models by touching a heated nichrome wire to the end of the fuel bed. The spread rate achieved a steady state condition shortly after ignition. Accurate measurements for pyrolysis front location requires complicated experimental procedures and is usually difficult as explained previously 5 . Here we measured a pyrolysis front location by taking photographs with a motor-driven camera which was automatically operated and recorded flame locations at two second intervals. Then, an average spread rate over two second periods was calculated. Maximum flame heights and flame depths were measured from the color photographs. The pyrolysis front along the fuel surface was nearly straight, so that edge effects were unimportant in these models. Irradiance received at the geometrically similar locations was measured by a radiometer of $120^{\circ}$ view angle. The detector was made of a thermopile and was calibrated against a black body source with a temperature range of $970 \mathrm{~K}$ to $1400 \mathrm{~K}$.

To check the effects of the fuel bed tilt angle, experiments were first run for the paper strip model. At a $60^{\circ}$ tilt angle, the flame abruptly increased its depth and its spread rate (as shown in Fig. 2), so that accurate spread rate measurements became difficult; the experiment 
was then terminated. Experimental results for the excelsior were only plotted for the two different bed tilt angles (horizontal and $\alpha=25^{\circ}$ ), since results obtained for angles $25^{\circ}<\alpha<60^{\circ}$ showed trends similar to those obtained for the paper strip model. Reproducibility was checked by repeating the same trial; the spread rate measured for the paper strip model differed by less than $5 \%$ and for the excelsior model by less than 15\%. The larger scattering observed for the excelsior fuel apparently occurs mainly because of nonhomogeneity of the excelsior element (wood) and nonuniformity of porosity. However the obtained data are in fact good enough to draw conclusions.

\subsection{Results}

Acceleratory spread occurred for both models during the initial period after ignition so the photographs were taken after the flame achieved a steady state condition. The photographs show that the pyrolysis line formed in the bed is nearly vertical for the paper strip model and approximately 45 degrees for the excelsior model. This difference can be explained as follows. Air entrainment through the excelsior fuel plays an important role in fuel pyrolysis because it has a porous structure with a large surface area to volume ratio. When tightly packed, its flammability property becomes similar to that of solid fuel. When the packing density decreases, the fuel exhibits a peculiar behavior known as smoldering (see Ohlemiller ${ }^{24}$ ). With further decrease of packing density, the fuel begins to exhibit high flammability characteristics, because porosity of the fuel allows enough air inside the fuel to oxidize the fuel elements. When the excelsior burns, the gas temperature near the pyrolyzing surface approaches nearly $1000 \mathrm{~K}$, so that the hot unburned gases and products move upward by buoyancy. This flow forms a decreased pressure region behind the pyrolys is plane. The presence of this region causes entrainment of the air into the pyrolysis surface. This air current is larger in the upper part of the pyrolysis plane than in the lower part, because of the smaller flow resistance there. The fuel pyrolysis rate is therefore laxger near the upper edge than at the lower edge so that the pyrolysis plane tilts toward the spread direction. The tilt angle is determined by an energy balance at the pyrolysis plane. Obviously, the more the pyrolysis plane tilts toward the spread direction, the more heat is required for the upper part of the pyrolysis plane to maintain the angle.

By contrast, the fuel structure of the paper strip model is nonporous, so that the negative pressure region is not formed inside the fuel. The fuel pyrolysis rate is controlled by heat transferred from the burning neighbor strips. It was observed during the experiment that flame spread occurred by nearly uniformal ignition of the side of the paper strip next to the burning one. Therefore nearly a vertical pyrolysis front line resulted, for all the bed tilt angles, $\alpha=0^{\circ}$ through $60^{\circ}$. Photographs taken during the tests indicate that all the flames retain turbulent flame characteristics. However, the flame shape for $\alpha-60^{\circ}$ is very different from the others. In this case, the flame spreads first along the thin surface of fuel bed in ahead of the vertical pyrolysis plane. Because of this over hang flame, the flame depth abruptly increased and considerably faster spread resulted, as seen in Figs, 2 and 3 . The flame attachment to a steep slope, $50-70$ degree $_{25}$ slope, has been observed by researchers for stationary fires; Albini commented it a fluid mechanical effect not unique to spreading fires. Figure 2 shows the measured average flame height and flame depth plotted against fuel bed height for three different sizes of fuel beds (specified in Table 1 ). The results showed that geometrical similarity was sustained 


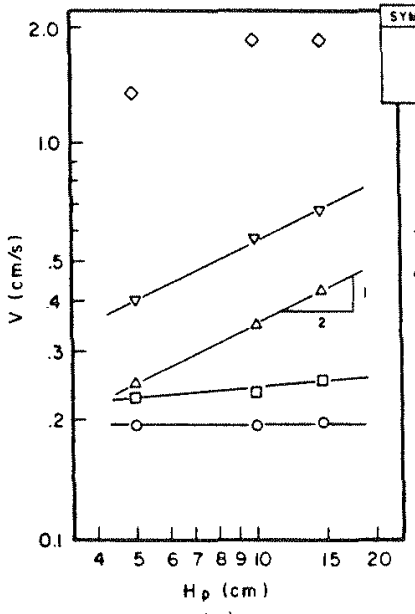

(o)

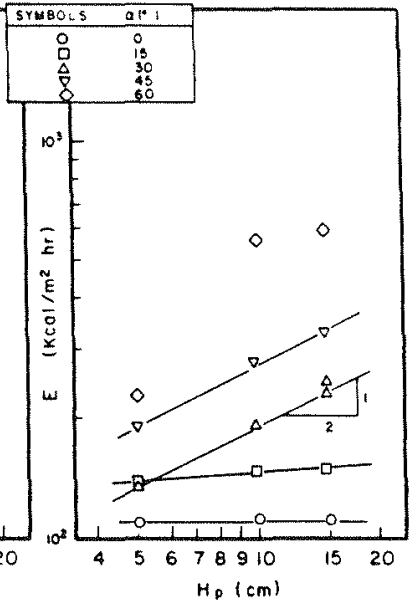

(b)

Fig. 3. As a function of fuel bed height, (a) average spread rate and (b) average irradiances received at $\Lambda d=55 \mathrm{~cm}$ for paper strip model $\left(A=15 / \mathrm{H}_{\mathrm{p}}\right)$.

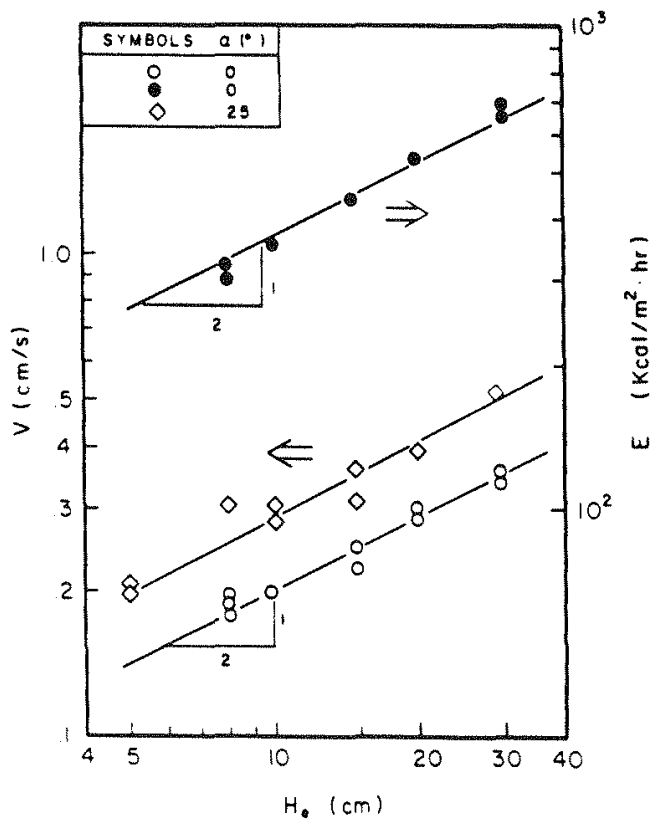

Fig. 4. Spread rate and irradiances received at $\Lambda d=200 \mathrm{~cm}$ as a function of fuel bed height for excelsior model $\left(\Lambda=30 / \mathrm{H}_{\mathrm{e}}\right)$.

for flames with the bed tilt angle, $0^{\circ} \leq \alpha \leq 45^{\circ}$. Figure 3 shows the measured average spread rate and radiant heat flux received at a geometrically similar location, the distance scaled in accordance with fuel bed size $\Lambda d=55 \mathrm{~cm}$, from the entire radiant source (flame and burning fuel), where $\Lambda-15 / H$ and $d$ is the distance between the radiometer location and flame? The results showed that both spread rate and irradiances (measured at a geometrically similar location) for $\alpha=0^{\circ}$ 
are independent of the size of the model and satisfies the law (4). That the Irradiance is igdgpendent of the size is the same as that obtained for the pool fires 8 , and suggesting that the scaling concept developed there is applicable to the type $\left(\alpha=0^{\circ}\right)$ of flame spread. While, the spread rate and irradiance for $30^{\circ} \leq \alpha \leq 45^{\circ}$ satisfy the 1aw (6), 8,9 suggesting that the scaling concept developed for the crib fires' 8,9 is applicable to the type $\left(30^{\circ} \leq \alpha \leq 45^{\circ}\right)$ of flame spread. However, the spread rate and irradiances for $0^{\circ}<\alpha<30^{\circ}$ are in a transient regime, and no clear classification was available. Figure 4 is plots of average spread rates and average irradiances as a function of fuel bed height for the excelsior. The measurements were made at a geometrically similar location (here $\Lambda \mathrm{d}=200 \mathrm{~cm}$ and $\Lambda=30 / \mathrm{H}_{\text {) }}$; the plots correspond to those of Fig. 3. Irradiances for the excelsior, however, are shown only for $\alpha$ $=0^{\circ}$ in Fig. 4, since approximately the same trend resulted for $\alpha=25^{\circ}$. The results showed that both spread rate and irradiances satisfy the law (6), and suggesting that the scaling laws developed for crib fires are available for this type of flame spread.

\section{The Grassland Fire and Corresponding Scale Models}

To apply the test results and the scaling laws obtained for the small/basic scale models to the larger/practical model, flame spread tests on grassland and on its reduced scale models were performed. The grassland is located in the suburbs of Tokyo and has approximately a $25^{\circ}$ slope angle and is covered with dry grass of approximately $40 \mathrm{~cm}$ in height. The measured average packing density of the grass was approximately $0.012 \mathrm{~g} / \mathrm{cm}^{3}$. The grass grew nearly uniformly on the land and was dry, although its moisture content was not measured. Fire was started at the lower end by igniting liquid fuel and spread occurred in a nearly still air environment. The experiment was performed on a clear day and wind was nearly still during the test. Vertical poles fixed equidistantly in the ground were used to obtain a reading of the flame front location. Spread rates were measured by recording the time required for the pyrolysis front to traverse the distance ( $1 \mathrm{~m}$ ) between each pole. Unfortunately, irradiances were not recorded in this test because of an instrumentation error.

Table 3. Configurations of grassland and its scale models.

\begin{tabular}{|lcccl|}
\hline & $\mathrm{H}(\mathrm{cm})$ & $\mathrm{H}_{\mathrm{e}}(\mathrm{cm})$ & $l_{2}(\mathrm{~m})$ & $\mathrm{L}(\mathrm{m})$ \\
\hline Prototype & 7.5 & 40.0 & 17.50 & 20.0 \\
$1 / 10$-Scale Model & 0.75 & 4 & 1.75 & 2.0 \\
$1 / 25$-Scale Model & 0.30 & 1.6 & 0.70 & 0.80 \\
\hline
\end{tabular}

Two geometrically similar grassland models with their reduced scale ratios to the prototype of $1 / 10$ and $1 / 25$ were designed; their dimensions are listed in Table 3 . Because the heat conducted through the ground is negligible, it was possible to use plaster rather than dirt as the material for the scale models. Their surface was then covered by the excelsior with the same packing density and with the same dryness as that of the basic scale model. The height of the excelsior was scaled in accordance with geometrical similarity, i.e., a 4 - cm-height for the larger model and a $1.6-\mathrm{cm}$-height for the small model. For the spread rate measurement, the method employed in Section 3 was applied.

Irradiances were measured by the same radiometer used for the basic model cests, at a geometrically similar location, $\Lambda d=1.0 \mathrm{~m}$, where $\Lambda=2 / \mathrm{L}$ and $L$ is listed in Table 3 . 


\subsection{Results and Comparison to Scaling Law Predictions}

Photographs of flame spreadings were taken for the one-tenth scale model in 20 seconds after uniform line ignition was established; while for the one-twenty fifth scale model in 12.6 seconds after ignition. The time ratio, $20 / 12.6=\sqrt{2.5}$ satisfies the law (7), and the two flames exhibited a geometrically similar shape. The average spread rate was calculated for the prototype and the models over the total bed length. We found that $V=16 \mathrm{~cm} / \mathrm{s}$ for the prototype, $V=5.0 \mathrm{~cm} / \mathrm{s}$ for the onetenth scale model and $V=3.0 \mathrm{~cm} / \mathrm{s}$ for the one-twenty fifth scale model. According to the law (6), the predicted spread rates are $V=3 \mathrm{~cm} / \mathrm{s} x \sqrt{25}$ $=15.0 \mathrm{~cm} / \mathrm{s}$ for the prototype and $\mathrm{V}=3 \mathrm{~cm} / \mathrm{s} \times \sqrt{2.5}=4.7 \mathrm{~cm} / \mathrm{s}$ for the one-tenth scale model, giving an excellent agreement with measurements.

It is interesting to predict spread rates for much larger scale fires. Law (6) was applied to typical grassland fires with pyrolysis front lengths of $200 \mathrm{~m}$ and $1000 \mathrm{~m}$ respectively, giving $\mathrm{V}-1.8 \mathrm{~km} / \mathrm{hr}$ for the former case and $\mathrm{V}-4 \mathrm{~km} / \mathrm{hr}$ for the latter case. These results caq beg compared with previous data for grassland and forest fires. Albini reported that fires raced through the chaparral fields of southern California at speeds up to $10 \mathrm{~km} / \mathrm{hr}$ and commented that grass fires have been checked at even faster speeds (possibly up to $20 \mathrm{~km} / \mathrm{hr}$ ). Our gredictions are well within these values. The Kita-Kyushu Fire Station

reported that a fire with approximately $1 \mathrm{~km}$ fire front length propagated down the slope with an average spread rate $2 \mathrm{~km} / \mathrm{hr}$ in a fire of $\mathrm{Mt}$. Nuki in Japan. Since the present discussion is for up-slope conditions, a direct comparison is not possible. However, the predicted spread rate from the scale model experiments can be understood as a reasonable bench mark value for a grassland fire under good burning

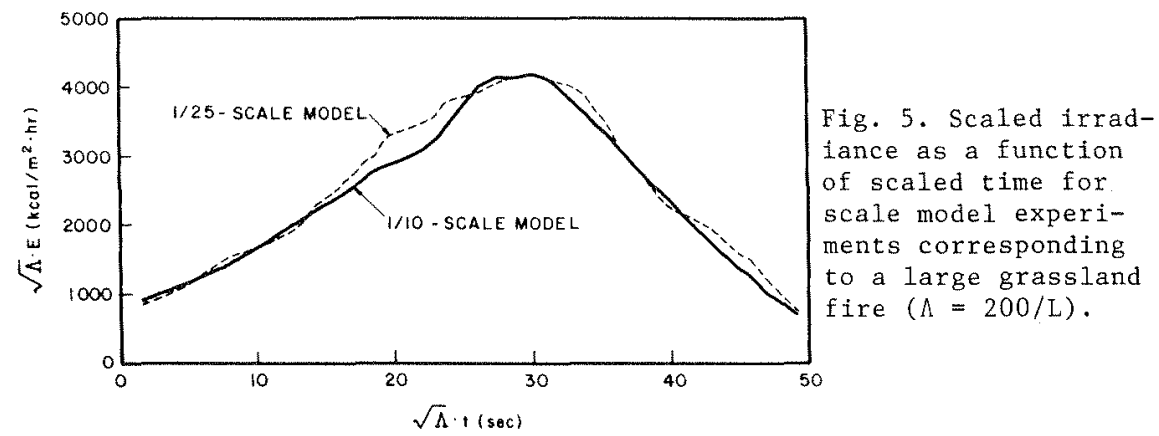

conditions. Irradiances measured for the two scale models at geometrically similar locations $(\Lambda \mathrm{d}=1 \mathrm{~m})$ were plotted on a coordinate of scaled irradiance versus scaled time in reference to the laws (6) and (7). The results are shown in Fig. 5 for the one-tenth scale model with a thick solid line and for one-twenty fifth scale model with a broken

line; excellent confirmation of the laws resulted.

The scaling laws predicted reasonable spread rates for fires discussed in the above. However, it should be noted that there is a definite applicable limit of the scaling laws, since the spread rate of a free-burning fire cappot increase indefinitely with the fire scale as suggested by Albini 25. Australian researchers studied the acceleration effects of fires ${ }^{15}$, and discussed several important factors such as 
moisture contents of fuel, fuel distribution, wind and slope. However, little has been done with fire scale and the applicable limit of the laws is left as unknown.

\section{CONCLUSIONS}

Scale model experiments have shown that, in agreement with our earlier studies 8, , two different types of scaling laws are available for turbulent flame spread on fuels with horizontal and up-slope configuration. The scaling laws were developed from the two different scaling concepts, whigh are essentially the same as those employed for the stationary fires 8,9 , and appeared to have appreciable versatality for other fire phenomena.

\section{ACKNOWLEDGEMENTS}

We would like to express our thanks to H. Sasaki and K. Akita for many helpful discussions. Special thanks are due to $S$. Soma for providing articles and for assisting our experiment. F.A. Albini provided us with very useful comments which helped to improve the contents largely. This research was supported by a special grant from Seikei University as a part of a joint research project under the contract \#4-21928.

\section{REFERENCES}

1. Williams, F.A., Sixteenth Int1. Symp. on Comb., 1976, p. 1281.

2. Fernandez-Pello, A.C. and Hirano, T., Comb. Sci. Tech., 32, 1, (1983).

3. Emori, I, and Saito, K., Fire Tech, , 18, 319 (1982).

4. Williams, F.A., Prog. Energ. Comb. Sci., 8, 317, (1982).

5. Saito, K., Quintiere, J, and Williams, F.A., Proc. of The First Int1. Symp. on Fire Safety Sci., 1985, p. 75.

6. Saito, K. Williams, F.A., Wichman, I.S. and Quintier, J.G., The 24-th ASME/AIChE National Heat Transfer Conference, 1987.

7. Albini, F.A., American Scientist, 72, 590, (1984).

8. Emori, I. and Saito, K., Comb. Sci. Tech., 31, 217, (1983).

9. Emori, I. and Saito, K., Bul1. of JSME, 29, 495, (1986).

10. Vogel, M. and Williams, F.A., Comb. Sci. Tech., 1, 429, (1970).

11. Atalleh, S., Pyrodynamics, 2, 53, (1965).

12. Fons, W.L., Glements, H.B. and George, P.M., Ninth Int1. Symp. on Comb., 1963, p. 866.

13. Yokahoma-shi Fire Station Office, Report on The Grassland Fire Test, 1980 .

14. Albini, F.A., Comb. Sci. Tech., 32, 277, (1983).

15. Luke, R.H. and McArther, A.G., Bushfires in Australla, Canberra: Austral. Gov. Publ. Serv. 1978.

16. Lee, B.T., Comb. Sci. Tech., 4, (1972).

17. Williams, F.A., Fire Res. Abst. Revs., 11, 1, (1969).

18. Spalding, D.B., Ninth Int1. Symp. on Comb., 1963, p. 883.

19. Emori, I. and Schuling, D.J., Scale Models in Engineering, The Theory and its Application, Pergamon Press, 1977.

20. Byram, G.M., in Forest Fire Control and Use (Kenneth P. Davis, Ed.), McGraw-Hi11, 1959.

21. Orloff, L., deRis, J, and Markstein, G.H., Fifteenth Int1. Symp. on Comb., 1975, p. 183.

22. Quintiere, J., Harkleroad, M. and Hasemi, Y., Comb. Sci. Tech., $48,191,(1986)$. 
23. Albini, F.A., Combustion and Flame, 43, 155, (1981).

24. Ohlemiller, T.J., Prog. Energ. Comb. Sci., 13, 97, (1987).

25. Albini, F.A., personal communication, 1987.

26. Albini, F.A., Comb. Sci. Tech., 42, 229, (1985).

27. Kita-Kyushu Fire Station Office, Report on the Fire of Mt. Nuki, 1979.

\section{NOMENCLATURE}

b space between each paper strip

$c_{p} \quad$ specific heat of gas at atmospheric pressure

$c_{2}^{p} \quad$ specific heat of fuel

$\mathrm{d}^{2}$ distance from flame to radiometer

E irradiance received by radiometers

$F_{b}$ buoyant force of air and gas

$F_{i}^{b} \quad$ inertial force of air and gas

$\mathrm{g}^{i}$ gravitational acceleration

$\mathrm{H}$ height

H flame height

$I^{f}$ fire intensity

$\mathrm{L}$ length of fuel bed

$L$ height of fire plume

$\mathrm{L}_{\mathrm{e}}^{\mathrm{a}}$ effective length where a mojor heat transfer occurs

Lw flame depth

$2_{2}^{W} \quad$ width of fuel bed

$\mathrm{Q}^{2} \quad$ heat generated

$Q_{c 1}$ heat stored in air and gas associated with temperature rise

$\mathrm{Q}_{\mathrm{c} 2}$ heat stored in unburned fuel

$Q_{r}^{c 2}$ radiant heat received by unburned fuel

$Q_{\lambda}^{r} \quad$ latent heat of fuel

$q_{f}$ heat value per unit mass of fuel

time

horizontal velocity of air and gas

velocity of flame spread

width of each paper strip

$\begin{array}{ll}\alpha & \text { inclination angle of fuel bed } \\ \Delta \theta_{1} & \text { temperature rise of air and gas }\end{array}$

$\Delta \theta_{2}$ temperature rise of fuel

$\lambda^{2}$ latent heat per unit mass of fuel

$\Lambda$ length scale factor

$\pi \quad$ pi-number

$\rho_{1}$ density of air and gas

$\Delta \rho_{1} \quad$ density change of $a \pm x$ and gas

density of fue 1

ratio of consumed fuel to the total available fuel

arbitrary function

Subscript

e excelsior

p paper strip 
